\title{
Photocatalytic ozonation of 2, 4-dichlorophenoxyacetic acid in water with a new $\mathrm{TiO}_{2}$ fiber
}

\author{
${ }^{1 *}$ R. R. Giri; ${ }^{2}$ H. Ozaki; ${ }^{1}$ S. Taniguchi; ${ }^{1}$ R. Takanami \\ ${ }^{1}$ New Industrial $R$ and D Center, Osaka Sangyo University, 3-1-1 Nakagaito, Daito City, 574-8530 Osaka, Japan \\ ${ }^{2}$ Department of Civil Engineering, Osaka Sangyo University, 3-1-1 Nakagaito, Daito City, 574-8530 \\ Osaka, Japan
}

Received 1 September 2007; revised 12 October 2007; accepted 9 November 2007; $\quad$ available online 26 December 2007

\begin{abstract}
More effective techniques are required to mineralize the increasing number of recalcitrant organic contaminants at low concentrations in the water environment using advanced oxidation process. Though relatively new, photocatalytic ozonation $\left(\mathrm{O}_{3} / \mathrm{UV} / \mathrm{TiO}_{2}\right)$ is considered superior to ozonation $\left(\mathrm{O}_{3}\right)$ and photocatalysis $\left.(\mathrm{UV} / \mathrm{TiO})_{2}\right)$, due to synergistic effects and use of immobilized $\mathrm{TiO}_{2}$ photocatalysts is a milestone in advance oxidation process. This article aimed to elucidate 2, 4-dichlorophenoxyacetic acid (2, 4-D) mineralization characteristics in low aqueous solutions by $\mathrm{O}_{3} / \mathrm{UV} / \mathrm{TiO}_{2}$ using the world's first high-strength $\mathrm{TiO}_{2}$ fiber catalyst in laboratory experiments. 2, 4-D degradation and TOC removal in $\mathrm{O}_{3}$, $\mathrm{UV} / \mathrm{TiO}_{2}$ and $\mathrm{O}_{3} / \mathrm{UV} / \mathrm{TiO}_{2}$ followed pseudo-first order reaction kinetic. The removal rates for 2, 4-D and TOC in $\mathrm{O}_{3} / \mathrm{UV} / \mathrm{TiO}_{2}$ were respectively about 1.5 and 2.4-fold larger than the summation of the corresponding values in $\mathrm{O}_{3}$ and $\mathrm{UV} / \mathrm{TiO}_{2}$. The $\mathrm{O}_{3} / \mathrm{UV} / \mathrm{TiO}{ }_{2}$ process was characterized by short-lived few aromatic intermediates, faster degradations of aliphatic intermediates and dechlorination as a major step in 2, 4-D mineralization. The significantly enhanced 2, 4-D mineralization in the process was attributed to increased ozone decomposition and reduced electron-hole recombination on $\mathrm{TiO}_{2}$ surface resulting to a large number of $\mathrm{OH}$ generation. The $\mathrm{O}_{3} / \mathrm{UV} / \mathrm{TiO}_{2}$ process with the $\mathrm{TiO}_{2}$ fiber catalyst was very promising with respect to the major challenges being faced in AOP involving $\mathrm{TiO}_{2}$, namely separation of powder catalyst in suspension and reduced efficiency of immobilized catalysts (e.g. $\mathrm{TiO}_{2}$ film/fiber).
\end{abstract}

Key words: Photocatalysis, degradation, hydroxyl radical, intermediates, rate constant, total organic carbon

\section{INTRODUCTION}

Ever-increasing use of chemicals and discovery of new recalcitrant organic contaminants in water environment have remained as major challenges in developing effective treatment methods for water and wastewater. A large number of organic contaminants are hazardous even at low concentration levels and stringent regulations are being enforced, especially in the industrialized nations for both conventional and non-conventional pollutants. Therefore, more effective methods are necessary for treating contaminated water and wastewater to meet the challenges. Ozonation $\left(\mathrm{O}_{3}\right)$ and photocatalysis $\left(\mathrm{UV} / \mathrm{TiO}_{2}\right)$ are widely investigated advanced oxidation processes (AOP) for treating contaminated waters (Djebbar and Sehili, 1998; Yao, et al., 1998; Drzewicz, et al., 2004; Singh and Muneer, 2004). Ozonation alone is less effective, since its

\footnotetext{
*Corresponding Author Email:

rabindra@cnt.osaka-sandai.ac.jp

Tel.: +81 72875 3001; Fax: +81 728753076
}

reaction with organic contaminants is selective (Brillas, et al., 2003; Agustina, et al., 2005; Li, et al., 2005) and generation of free radicals from its decomposition takes place only at elevated $\mathrm{pH}$ conditions (Munter, 2001). Oxidation of contaminants in $\mathrm{UV} / \mathrm{TiO}_{2}$ system involves free hydroxyl radical ( $\mathrm{OH})$, but separation of $\mathrm{TiO}_{2}$ catalyst in suspension has been a major obstacle. Although recent developments in $\mathrm{TiO}_{2}$ film and fiber catalysts can overcome the problem, mere photocatalysis is reported to be less efficient for several organic contaminants (Agustina, et al., 2005; Li, et al., 2005; Terashima, et al., 2006). Photocatalytic ozonation $\left(\mathrm{O}_{3} / \mathrm{UV} / \mathrm{TiO}_{2}\right)$ is emerging as a more promising oxidation method for refractory organic contaminants due to a large number of $\mathrm{OH}$ generation (Agustina, et al., 2005; Beltran, et al., 2005; Li ,et al., 2005; Farre, et al., 2005). Few literatures are available on the $\mathrm{O}_{3} / \mathrm{UV} / \mathrm{TiO}_{2}$ process, because its use is relatively new, while successful use of $\mathrm{TiO}_{2}$ fiber catalyst is expected to be 
a milestone in practical applications of the $\mathrm{UV} / \mathrm{TiO}_{2}$ and $\mathrm{O}_{3} / \mathrm{UV} / \mathrm{TiO}_{2}$ processes. This article aimed to investigate degradation characteristics of low concentration $(\approx 45 \mu \mathrm{M}) 2$, 4-dichlorophenoxyacetic acid (2, 4-D) in aqueous solution by the $\mathrm{O}_{3} / \mathrm{UV} / \mathrm{TiO}_{2}$ process using the world's first high-strength $\mathrm{TiO}_{2}$ fiber catalyst (Ishikawa, 2004) developed by Ube Industries Ltd., Japan, with laboratory batch-experiments.

\section{MATERIALS AND METHODS}

The 2, 4-D standard (Cica-Reagent) was obtained from Kanto Chemical Co., Inc. $\mathrm{Na}_{2} \mathrm{SO}_{3}$ solution $(1.0 \mathrm{~g} / \mathrm{L})$ and Spectroquant ${ }^{\circledR}$ Picco Colorimeter test kit (Merck, Germany) which were respectively used to quench and measure residual dissolved ozone in samples in $\mathrm{O}_{3}$ and $\mathrm{O}_{3} / \mathrm{UV} / \mathrm{TiO}_{2}$ experiments. Other reagents were of HPLC grade obtained from Wako Pure Chemicals Ltd., Japan. Carrier gas flow from ozone generator to reactor was regulated with a flow meter, while $\mathrm{O}_{3}$ concentration in the carrier gas was continuously monitored using an ozone measuring device(EG-600, EBARA JITSUGYO Co. Ltd., Japan). A Pyrex glass reactor (8.0 l capacity, ID: $18.4 \mathrm{~cm}, \mathrm{~h}: 30 \mathrm{~cm}$ ) with centrally placed tubular jacket (OD: $6.2 \mathrm{~cm}$ ) and six circular ports (OD: $2.8 \mathrm{~cm}$ ) at the top was used for batch experiments. $\mathrm{TiO}_{2}$ fiber catalyst $(20 \mathrm{~cm} \times 25 \mathrm{~cm}$ sheets) was supplied by Ube Industries Ltd., Japan. A cylindrical catalyst module (OD: $18.4 \mathrm{~cm}$, h: $30 \mathrm{~cm}$ ) was prepared using the catalyst and stainless steel wire mesh (3 mm $\times 3 \mathrm{~mm}$ opening). Ozone was generated by passing air $\left(21 \% \mathrm{O}_{2}+79 \% \mathrm{~N}_{2}\right)$ through an ozone generator (Nippon Ozone Co., Ltd.). A UV tube lamp (10 W, 254 nm, UVL10DL-12, SEN Lights Corporation, Japan) was the source of irradiation in $\mathrm{UV} / \mathrm{TiO}_{2}$ and $\mathrm{O}_{3} / \mathrm{UV} / \mathrm{TiO}_{2}$ processes. Headspace gas in the reactor was continuously pumped, dried and passed through a packed tower to absorb residual $\mathrm{O}_{3}$ gas.

Seven and half liter of about $45 \mu \mathrm{M} 2$, 4-D solution without initial $\mathrm{pH}$ adjustment was poured into the reactor. Ozone generator, carrier gas flow meter, ozone concentration monitoring device, reactor, pump and absorption tower were connected in series. The solution was continuously mixed with a magnetic stirrer with the same speed in all the experiments. The samples were taken at $20 \mathrm{~min}$. interval for analysis, while all of the experiments were carried out for a duration of $2 \mathrm{~h}$. The catalyst module was placed inside the reactor in the $\mathrm{UV} / \mathrm{TiO}_{2}$ and $\mathrm{O}_{3} / \mathrm{UV} / \mathrm{TiO}_{2}$ experiments. Carrier gas flow rate and ozone concentration in it were respectivly maintained at $1.0 \mathrm{~L} / \mathrm{min}$. and $2.0 \mathrm{mg} / \mathrm{L}$ throughout the experiments in the $\mathrm{O}_{3}$ and $\mathrm{O}_{3} / \mathrm{UV} / \mathrm{TiO}_{2}$ processes. The ozone concentration in carrier gas was regulated by varying electric voltage in ozone generator.

The samples were analyzed for remaining 2, 4-D and both aromatic and aliphatic intermediates using HPLC with UV detector (Model: D-7000, Hitachi, Japan). Inertsil ODS-3V column $(150 \mathrm{~mm} \times 3 \mathrm{~mm}$ ID $\times 5 \mu \mathrm{m})$ with $35^{\circ} \mathrm{C}$ oven temperature, $20 \mu \mathrm{L}$ sample volume and $\mathrm{CH}_{3} \mathrm{CN}: \mathrm{H}_{2} \mathrm{O}: \mathrm{CH}_{3} \mathrm{COOH}=50: 49: 1(\mathrm{v} / \mathrm{v})$ mobile phase at $0.40 \mathrm{~mL} / \mathrm{min}$. flow rate was employed for aromatic intermediates including 2, 4-D at $254 \mathrm{~nm}$. Supelcogel C-610H $(30 \mathrm{~cm} \times 7.8 \mathrm{~mm}$ ID $\times 9 \mu \mathrm{m})$ together with Supelguard C-610H (5 cm $\times 4.6 \mathrm{~mm}$ ID) columns with $30^{\circ} \mathrm{C}$ oven temperature, $20 \mu \mathrm{L}$ sample volume and $0.1 \%$ $\mathrm{H}_{3} \mathrm{PO}_{4}$ in water (v/v) mobile phase at $0.50 \mathrm{~mL} / \mathrm{min}$. flow rate were used for aliphatic intermediates at $210 \mathrm{~nm}$. The detected intermediates of 2, 4-D oxidation were identified by matching peak retention time (RT) of oxidized 2, 4-D samples with the peaks of various known standards. Total organic carbon (TOC) analyzer (TOC-V ${ }_{\mathrm{CSH}}$ Shimadzu, Japan) was used to measure TOC while Ion Chromatograph with conductivity detector (Model: L-7000, Hitachi, Japan), GL-IC-A25 column (150 $\mathrm{mm} \times 4.6 \mathrm{~mm}$ ID), $40^{\circ} \mathrm{C}$ oven temperature and 4.0 $\mathrm{mM} \mathrm{Na} \mathrm{CO}_{3}$ solution (in water) mobile phase at $1.0 \mathrm{~mL} / \mathrm{min}$. flow rate were used to measure chloride ion concentration in the samples. Residual aqueous phase ozone in the samples was measured by photometric diphenylen-diamine-based (DPD) method at $528 \mathrm{~nm}$ UV wave length.

\section{RESULTS AND DISCUSSION}

All the experiments were carried out in triplicate and average values of the results are presented in figures while the error bars in the figures indicate standard deviations. Average initial $\mathrm{pH}$ values of about $45 \mu \mathrm{M}$ 2, 4-D solutions in $\mathrm{O}_{3}, \mathrm{UV} / \mathrm{TiO}_{2}$ and $\mathrm{O}_{3} / \mathrm{UV} / \mathrm{TiO}_{2}$ processes were $4.36,4.32$ and 4.33 , respectively, which gradually decreased during a $2 \mathrm{~h}$. oxidation. The $\mathrm{O}_{3} / \mathrm{UV} / \mathrm{TiO}_{2}$ and $\mathrm{UV} / \mathrm{TiO}_{2}$ processes have the most and least efficiencies respectively for 2, 4-D oxidation (Fig. 1). About $54 \%$ and $83 \%$ of 2 , 4 -D was oxidized in $\mathrm{UV} / \mathrm{TiO}_{2}$ and $\mathrm{O}_{3}$ at the end of the $2 \mathrm{~h}$. oxidation, while one hundred percent of the 2, 4-D degraded in less than two hours in $\mathrm{O}_{3} / \mathrm{UV} / \mathrm{TiO}_{2}$. The half-life periods for 2, 4-D in the $\mathrm{O}_{3}, \mathrm{UV} / \mathrm{TiO}_{2}$ and $\mathrm{O}_{3} / \mathrm{UV} / \mathrm{TiO}_{2}$ processes were about 60, 110 and $28 \mathrm{~min}$., respectively. 2, 4-D oxidations in all of the three processes were well- 
Int. J. Environ. Sci. Tech., 5 (1), 17-26, Winter 2008

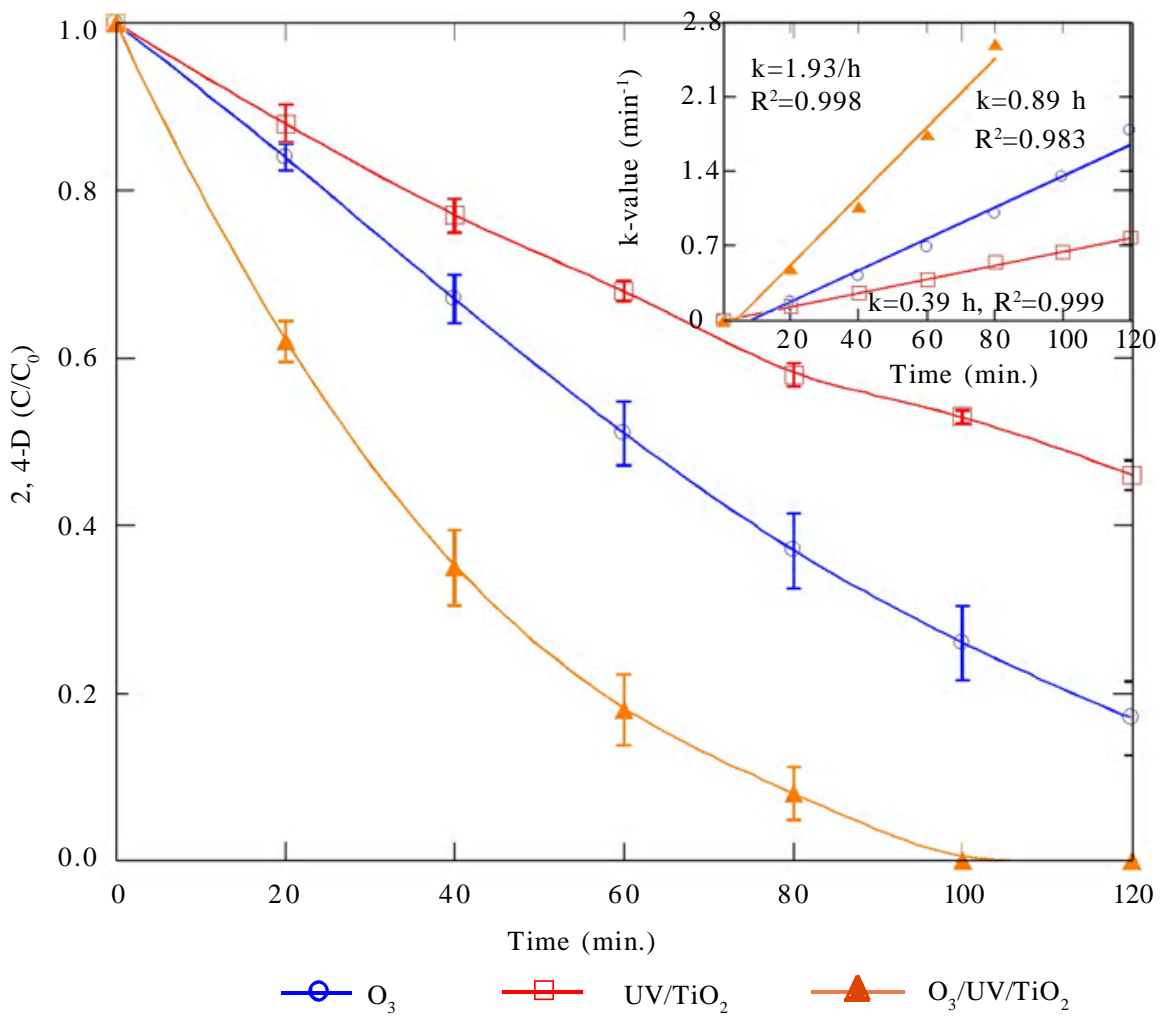

Fig. 1: Relative 2, 4-D concentration profiles in different oxidation systems

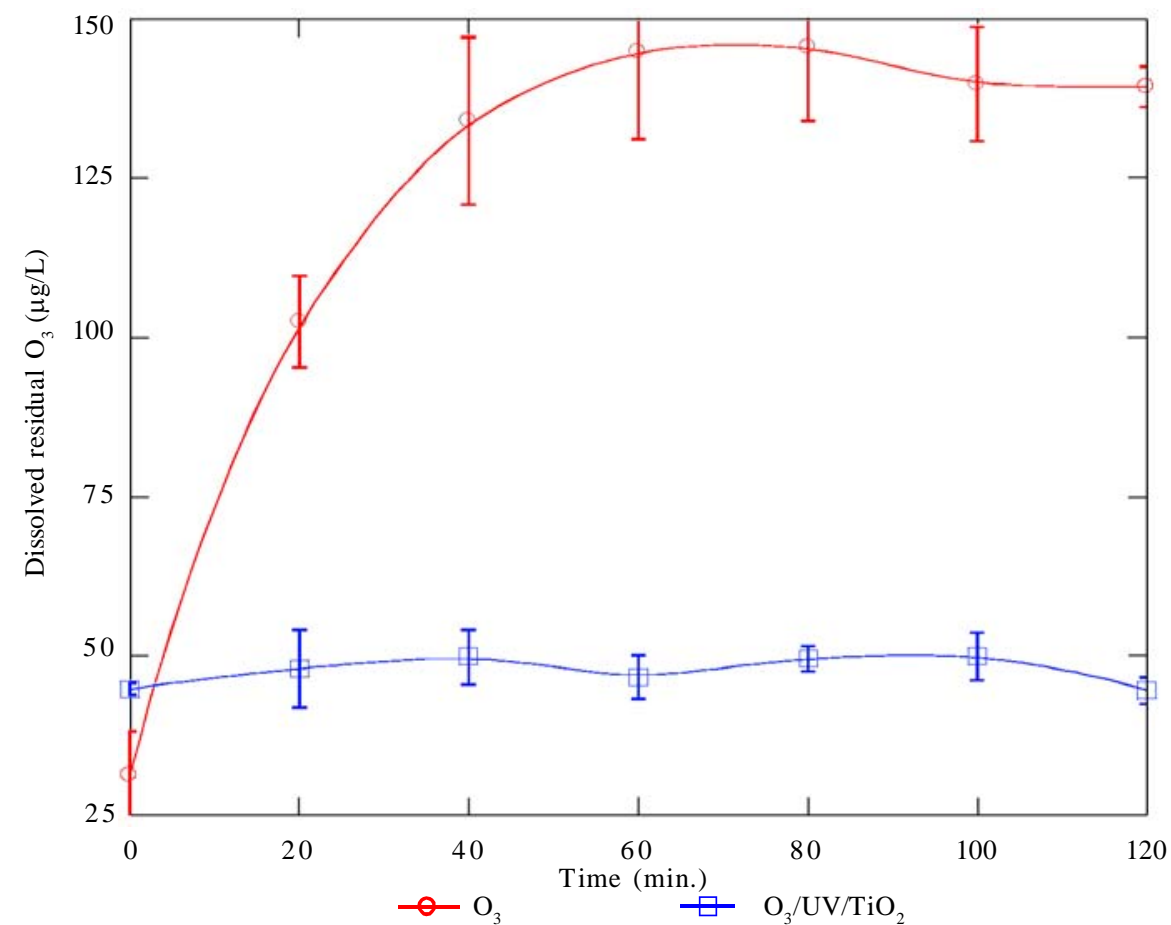

Fig. 2: Residual dissolved ozone concentration profiles during 2, 4-D mineralization 
described by pseudo-first order reaction kinetic (Fig. 1). The degradation rate (k) values in $\mathrm{UV} / \mathrm{TiO}_{2}, \mathrm{O}_{3}$ and $\mathrm{O}_{3} / \mathrm{UV} / \mathrm{TiO}_{2}$ were $0.39,0.89$ and $1.93 / \mathrm{h}$, respectively. The value for $\mathrm{O}_{3} / \mathrm{UV} / \mathrm{TiO}_{2}$ was about 1.5 times higher than the summation of the values for the other two processes. Thus, $\mathrm{O}_{3} / \mathrm{UV} / \mathrm{TiO}_{2}$ using $\mathrm{TiO}_{2}$ fiber catalyst was found to be a very effective process to degrade the model pollutant in low aqueous solution. Though a positively charged hole on $\mathrm{TiO}_{2}$ surface in $\mathrm{UV} / \mathrm{TiO}_{2}$ process is mentioned to possess the highest oxidation power (Munter, 2001), its role on oxidation of micropollutants is not well explained. Therefore, $\mathrm{OH}$ is considered to be the sole oxidizing species, which has the second highest oxidation power (Munter, 2001). Despite the non-selective reaction and high oxidation power of $\cdot \mathrm{OH}, \mathrm{UV} / \mathrm{TiO}_{2}$ with fiber catalyst was found to be rather a slow process in this investigation, which is consistent with the earlier results with $\mathrm{TiO}_{2}$ fiber, powder and film catalysts (Beltran, et al., 2005; Li, et al., 2005; Terashima, et al., 2006). Generation and utilization of $\mathrm{OH}$ are two important steps in oxidations involving $\mathrm{OH}$. However, the quantification of $\cdot \mathrm{OH}$ in a process is quite complicated due to its very short life. Chloride ions at high concentrations are reported to have scavenging effect on $\mathrm{OH}$ (Kiwi, et al., 2000). Theoretically, about $90.48 \mu \mathrm{M}$ of chloride ions can be liberated from $45 \mu \mathrm{M}$ of 2 , 4-D oxidation. Photocatalytic oxidation experiments with $45 \mu \mathrm{M} 2,4-\mathrm{D}, \mathrm{TiO}_{2}$ fiber catalyst and various initial chloride ion concentrations $(0,56,85,113$ and $141 \mu \mathrm{M})$ were also carried out. The results (not shown) exhibited no significant effect of chloride ions on 2, 4-D oxidation. The slow 2, 4-D oxidation in the $\mathrm{UV} / \mathrm{TiO}_{2}$ process was presumably due to a less number of $\mathrm{OH}$ generation. Recombination of electrons and positive holes formed on $\mathrm{TiO}_{2}$ surface are considered as a possible reason for a less number of $\mathrm{OH}$ in the process (Agustina, et al., 2005; Farre, et al., 2005). The 2, 4-D degradation rates in $\mathrm{O}_{3}$ and $\mathrm{O}_{3} /$ $\mathrm{UV} / \mathrm{TiO}_{2}$ were about 2.3 and 4.9 times of $\mathrm{UV} / \mathrm{TiO}_{2}$, while the value for $\mathrm{O}_{3} / \mathrm{UV} / \mathrm{TiO}_{2}$ was about 2.2 times of $\mathrm{O}_{3}$. Since the oxidations took place below $4.36 \mathrm{pH}$ value in the $\mathrm{O}_{3}$ process, direct ozonation of 2, 4-D was most likely a major degradation mechanism (Beltran, et al., 2005). The enhanced degradation in $\mathrm{O}_{3} / \mathrm{UV} / \mathrm{TiO}_{2}$ can be attributed to ozone decomposition resulting in an increased $\mathrm{OH}$ production (Agustina, et al., 2005; Beltran, et al., 2005). Dissolved residual ozone concentrations in $\mathrm{O}_{3} / \mathrm{UV} / \mathrm{TiO}_{2}$ were significantly smaller than that in $\mathrm{O}_{3}$ and almost constant throughout the experiments (Fig. 2). This presumably is the result of its decomposition, while the values in the $\mathrm{O}_{3}$ process drastically increased during the first-half of the experiment and then remained almost stagnant. Farre, et al., (2005) also argued that the presence of dissolved ozone in irradiated $\mathrm{TiO}_{2}$ aqueous suspension not only increases $\mathrm{OH}$ production but also decreases the recombination of electrons and positive holes on the $\mathrm{TiO}_{2}$ surface.

Since all the detected intermediates were not identified, their abundance profiles with time are used for discussion in this section. Ozonation was characterized by the largest number of intermediates including eight aromatics (Fig. 3) and ten aliphatics (Fig. 4). The two identified aromatics (2, 4dichlorophenol (2, 4-DCP) and benzyl alcohol (BA)) were relatively at low concentrations while the two unknowns ( $\mathrm{RT} \approx 4.5$ and $6.6 \mathrm{~min}$.) appeared to be the main (Fig. 3). The least number of intermediates was detected in the UV/TiO 2 process (Fig. 5), where 2, 4DCP was the main aromatic intermediate while benzyl alcohol at low concentrations was also detected at the end of the experiments. Maleic acid and one unknown ( $\mathrm{RT} \approx 15.1 \mathrm{~min}$.) were aliphatic intermediates in the process. Three aromatics (2, 4-DCP, BA and one unknown $(\mathrm{RT} \approx 4.1 \mathrm{~min}$.)) and nine aliphatics, including the four unknowns (Fig. 6), were detected in the $\mathrm{O}_{3} /$ $\mathrm{UV} / \mathrm{TiO}_{2}$ process, where the number was larger than that in $\mathrm{UV} / \mathrm{TiO}_{2}$ and smaller than that in $\mathrm{O}_{3}$. 2, 4-DCP, which is more toxic than the parent compound and was the major aromatic byproduct in the $\mathrm{UV} / \mathrm{TiO}_{2}$ process. Despite increased toxicity due to the 2, 4-DCP formation, the least number of intermediates may be interpreted as a result of shorter paths for 2, 4-D degradation. The increasing intensity profiles of both aromatic and aliphatic intermediates until the end of the experiments (Fig. 5) exhibited that $\mathrm{UV} / \mathrm{TiO}_{2}$ is a slow process in terms of 2, 4-D mineralization. In contrast to $\mathrm{UV} / \mathrm{TiO}_{2}$, most of the aromatic intermediates detected in ozonation reached to their highest intensity values, and then decreased before the end of the experiments (Fig. 3). But the intensity values for all of the aliphatic intermediates continued its increasing to the end (Fig. 4). The largest number of aliphatic intermediates was attributed to the selective reaction of ozone at acidic or neutral $\mathrm{pH}$ conditions resulting in the formation of carboxylic acids as the end products (Agustina, et al., 2005). The slow degradations of the carboxylic acids were also presumably due to the 
Int. J. Environ. Sci. Tech., 5 (1), 17-26, Winter 2008
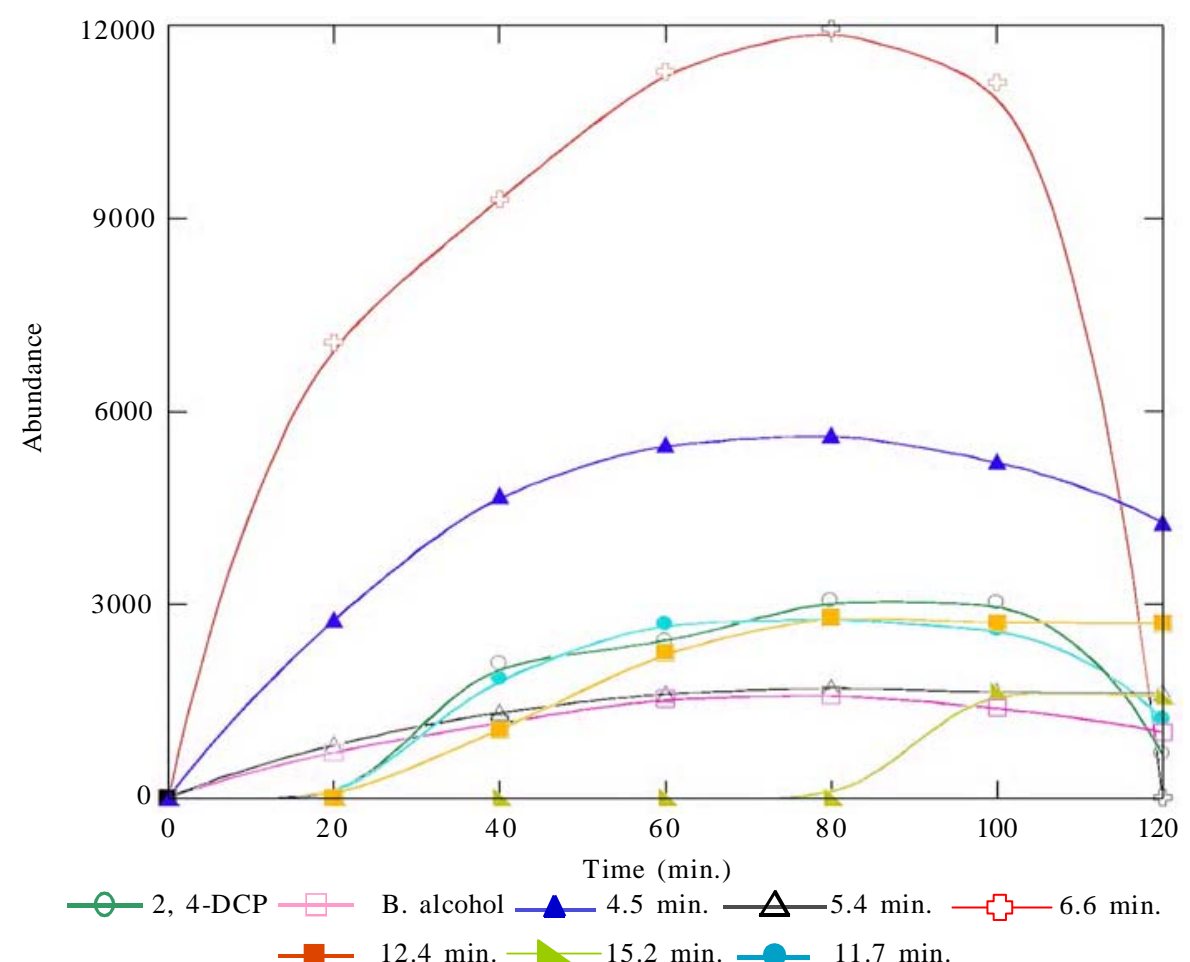

Fig. 3: Aromatic intermediates detected in ozonation of 2, 4-D

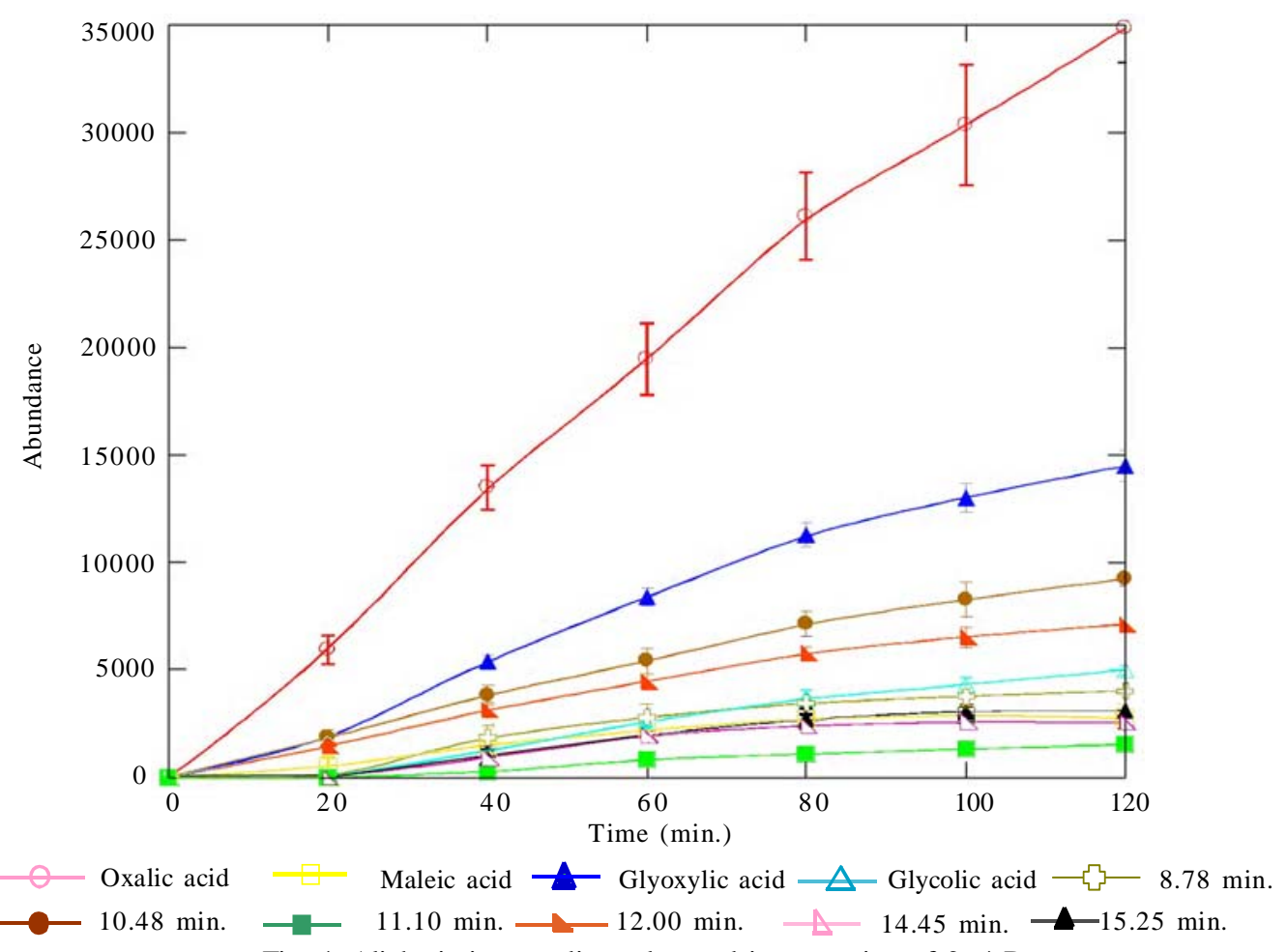

Fig. 4: Aliphatic intermediates detected in ozonation of 2, 4-D 
R. R. Giri, et al.

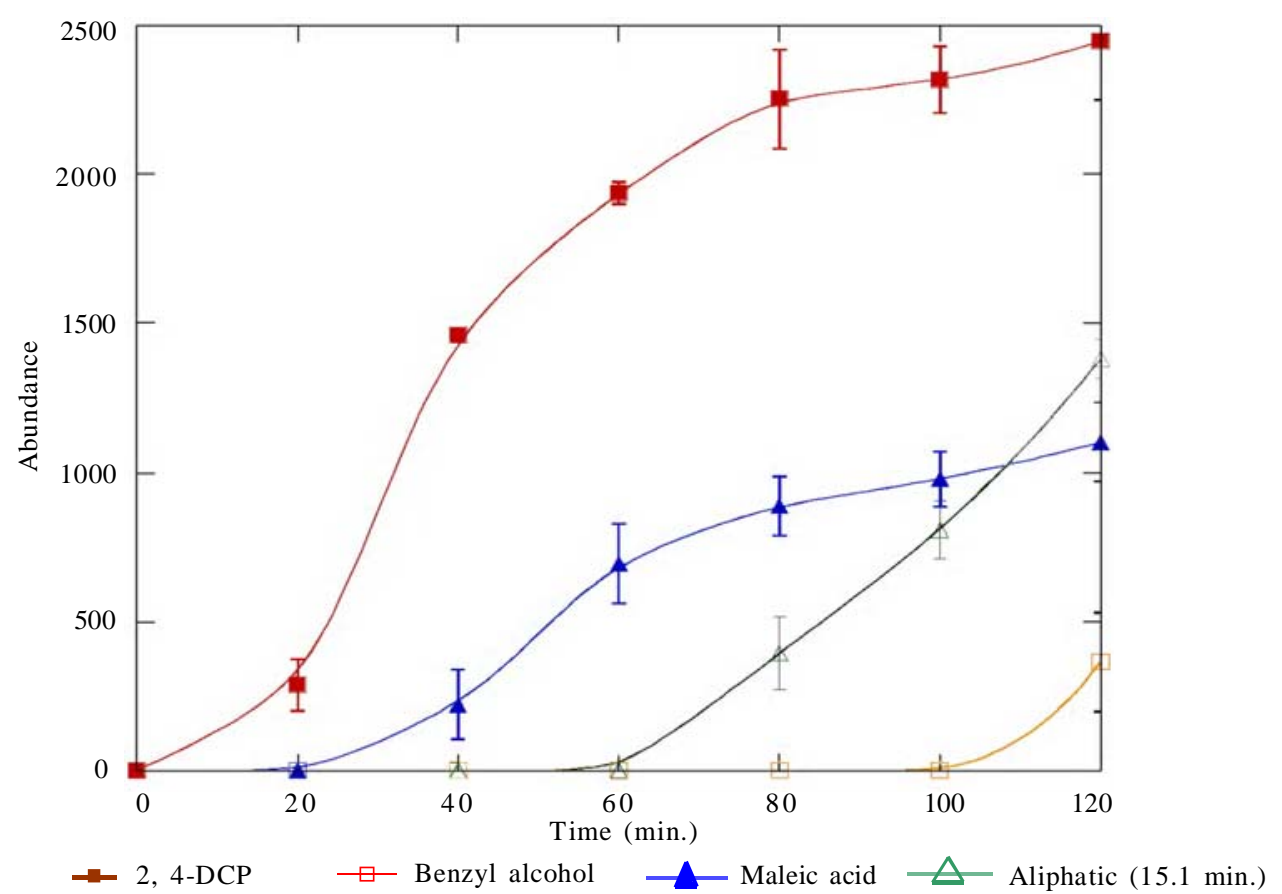

Fig. 5: Intermediates detected in photocatalytic oxidation of 2, 4-D

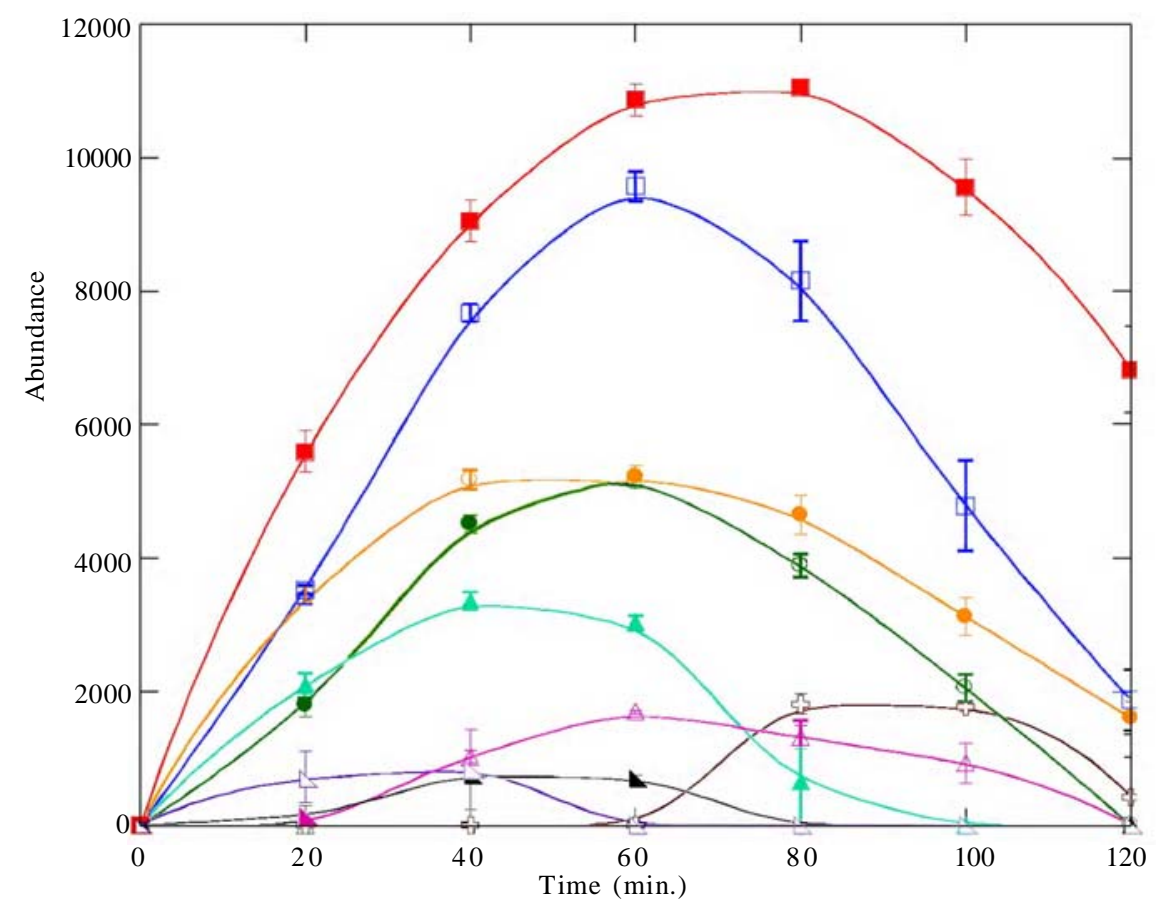

$\triangle 12.00$ min. $\quad$ - Oxalic acid $\square$ Maleic acid $\square$ Glyoxylic acid

$\triangle$ Fumaric acid $\preceq-$ Formic acid $\longrightarrow 14.33 \mathrm{~min} . \longrightarrow 15.25 \mathrm{~min} . \longrightarrow 10.21 \mathrm{~min}$.

Fig. 6: Aliphatic intermediates detected in photocatalytic ozonation of 2, 4-D 
selective reaction. Though several aliphatic intermediates were not identified (Fig. 4), the formation of saturated carboxylic acids in the process could have resulted in the slow oxidation, since the unsaturated carboxylic acids are relatively unstable and get oxidized more easily than the saturated ones (Jung, 2001). Low concentrations of the three aromatic intermediates in $\mathrm{O}_{3} / \mathrm{UV} / \mathrm{TiO}_{2}$ (not shown) were present for a short period indicating their fast oxidations. Despite a relatively large number of aliphatic intermediates in the process, their intensities reached to the peak values at the middle of the experiments and decreased significantly by the end (Fig. 6). Thus, the detected intermediates in the $\mathrm{O}_{3} / \mathrm{UV} / \mathrm{TiO}_{2}$ process were oxidized faster than that in the other two processes presumably due to the increased $\mathrm{OH}$ generation and its effective use in the oxidation. In contrast to ozonation, the nature of aliphatic intermediates did not appear to be an important factor for their oxidation in the $\mathrm{O}_{3} / \mathrm{UV} / \mathrm{TiO}_{2}$ process.

Though 2, 4-D oxidation in $\mathrm{O}_{3}$ was more than two folds larger than that in $\mathrm{UV} / \mathrm{TiO}_{2}$, no significant difference in TOC removals between these two processes was observed through the first half of the experiments (Fig. 7). Ozonation then appeared to be less efficient compared to $\mathrm{UV} / \mathrm{TiO}_{2}$ and the difference between them gradually increased till the end. TOC removals in these processes by the end of the experiments were about $17 \%$ and $23 \%$, respectively. Similar to 2, 4-D degradation, $\mathrm{O}_{3} / \mathrm{UV} / \mathrm{TiO}_{2}$ was the most effective in terms of TOC removal among the three processes (Fig. 7), where the removal was about $67 \%$ at the end of the $2 \mathrm{~h}$. oxidation. But the $\mathrm{O}_{3}$ and $\mathrm{UV} / \mathrm{TiO}_{2}$ processes appeared to be very inefficient in terms of TOC removal. TOC removals by the three processes were well described by pseudo first-order reaction kinetic (inset of Fig. 7). The removal rate k values for $\mathrm{O}_{3}, \mathrm{UV} / \mathrm{TiO}_{2}$ and $\mathrm{O}_{3} / \mathrm{UV} / \mathrm{TiO}_{2}$ were about $0.09,0.14$ and $0.56 / \mathrm{h}$, respectively. The $\mathrm{k}$ value for $\mathrm{O}_{3} / \mathrm{UV} / \mathrm{TiO}_{2}$ was about 2.4 folds higher than the summation of $k$ values for the remaining two processes. Thus, 2, 4-D mineralization in the $\mathrm{O}_{3} / \mathrm{UV} / \mathrm{TiO}_{2}$ process using $\mathrm{TiO}_{2}$ fiber catalyst was very effective due to the synergistic effects of photocatalysis and ozonation. Two possible mechanisms are proposed for the enhanced mineralization of organics in the combined process (Agustina, et al., 2005). Dissolved ozone can easily accept electrons produced on $\mathrm{TiO}_{2}$ surface, which reduces the possibility of their recombination with positive holes resulting in a large number of $\cdot \mathrm{OH}$ formation. A large number of hydrogen peroxide and OH can also be produced from dissolved ozone as a result of UV irradiation. More than one parallel path for $\mathrm{OH}$ generation is proposed in the combined process (Beltran, et al., 2005).

Though ozone photolysis is a slow process in the beginning, it is considered to be an important mechanism for $\mathrm{OH}$ generation after a few minutes. With high extinction coefficient value of ozone at $254 \mathrm{~nm}$ wave length $(\varepsilon=3300 / \mathrm{M} / \mathrm{cm})$, a significantly large number of $\mathrm{OH}$ is generated from its photolysis (Munter, 2001). The presence of $\mathrm{TiO}_{2}$ implies some adsorption steps followed by surface reactions though there is a lack of kinetic information (Beltran, et al., 2005). Reaction between ozone and titanium yields adsorbed ozonide ion radical $\left(\mathrm{O}_{3}^{--}\right)$, which is another source of $\cdot \mathrm{OH}$. Thus, three parallel paths of $\cdot \mathrm{OH}$ generation are available in the $\mathrm{O}_{3} / \mathrm{UV} / \mathrm{TiO}_{2}$ process in addition to direct photolysis and ozonation of 2, 4-D and its intermediates. The almost constant and significantly smaller dissolved residual ozone values for the process (Fig. 3) were presumably the result of ozone photolysis and/or adsorption followed by its decomposition. Reactions of organics containing $\mathrm{C}-\mathrm{H}$ or $\mathrm{C}-\mathrm{C}$ multiple bonds with OH generally proceed with larger rate constants $\left(\sim 10^{10} / \mathrm{M} / \mathrm{S}\right)$ and therefore their oxidations are usually limited by $\mathrm{OH}$ generation and reaction with $\mathrm{OH}$ scavengers (Haag and Yao, 1992). Carbonate, bicarbonate and high concentrations of chloride ions are considered as $\cdot \mathrm{OH}$ scavengers, but their scavenging effects in these experiments were presumably insignificant. Reaction rates of ozone with aromatics including phenols are very small (by $6 \sim 11$-log orders) compared to $\mathrm{OH}$ (Munter, 2001). Therefore, the generation of a large number of $\mathrm{OH}$ from the parallel paths and high reaction rates of $\cdot \mathrm{OH}$ with 2, 4-D and its degradation intermediates presumably resulted in the enhanced 2, 4-D mineralization in the $\mathrm{O}_{3} / \mathrm{UV} / \mathrm{TiO}_{2}$ process.

The chloride content in hazardous organics is considered as a measure of their toxicity and hence dechlorination is a very important step in their oxidations. Dechlorination in a sample was calculated as the ratio of free chloride ion concentration in the sample to the theoretical chlorine content in 2, 4-D before oxidation. Dechlorination profiles for the three oxidation processes in this investigation (Fig. 8) exhibited that $\mathrm{O}_{3}$ was more efficient than $\mathrm{UV} / \mathrm{TiO}_{2}$ and 


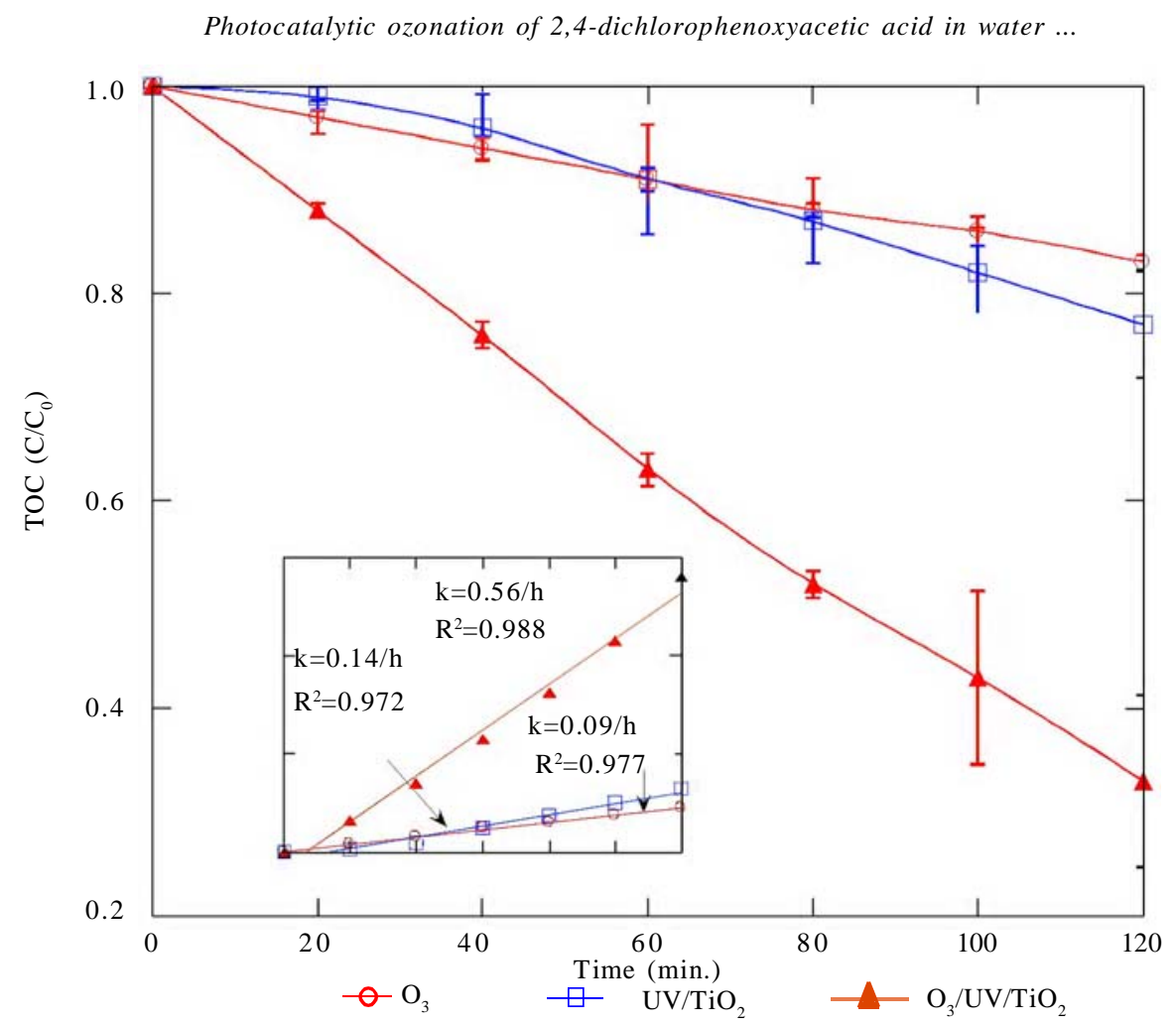

Fig. 7: Relative TOC concentration profiles during 2, 4-D mineralization

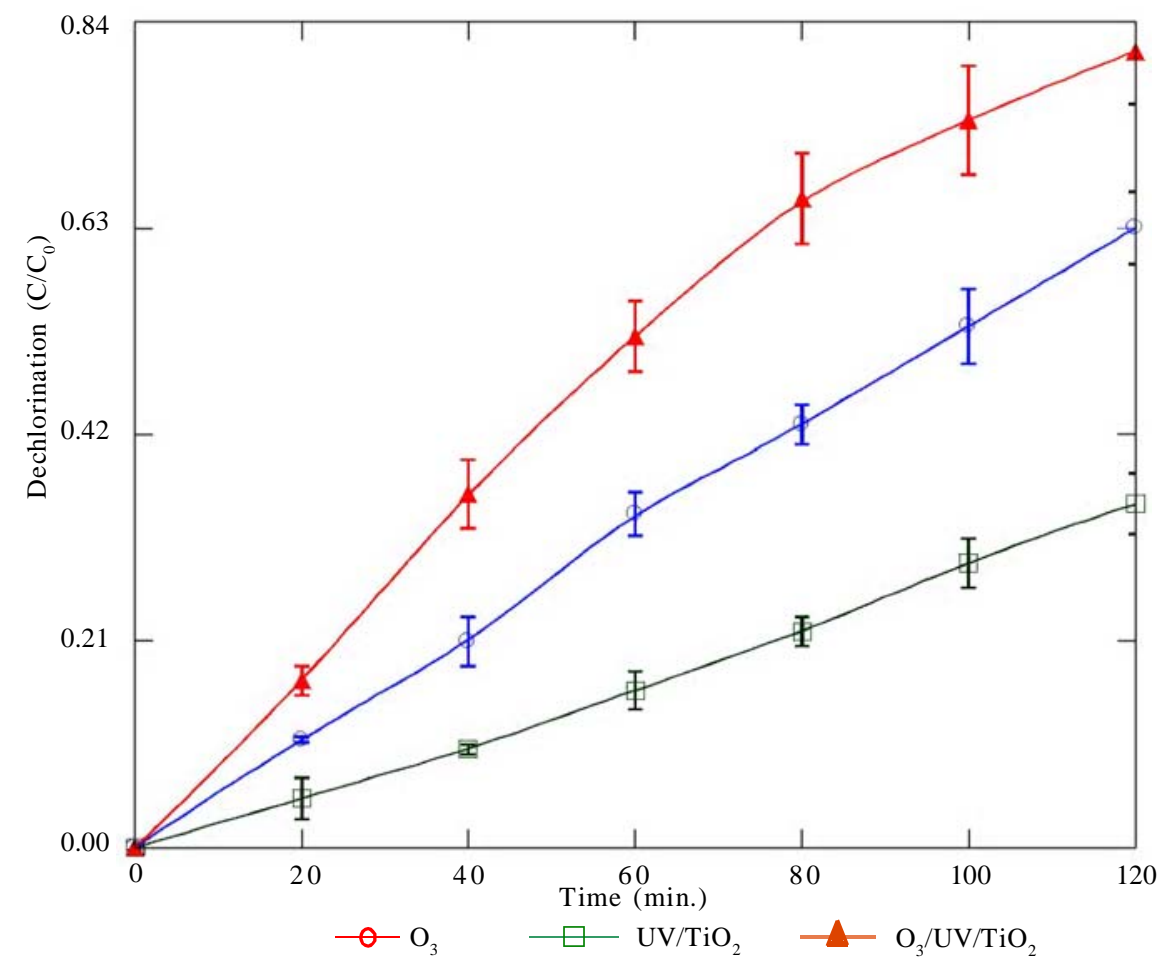

Fig. 8: Relative chloride ion concentration profiles during 2, 4-D mineralization 
$\mathrm{O}_{3} / \mathrm{UV} / \mathrm{TiO}_{2}$ was the most efficient. Dechlorination values for the $\mathrm{O}_{3}, \mathrm{UV} / \mathrm{TiO}_{2}$ and $\mathrm{O}_{3} / \mathrm{UV} / \mathrm{TiO}_{2}$ processes at the end of the $2 \mathrm{~h}$. experiments were about 35,63 and $81 \%$, respectively. The average dechlorinations during the experiments in $\mathrm{O}_{3} / \mathrm{UV} / \mathrm{TiO}_{2}$ and $\mathrm{O}_{3}$ were about three and two folds the value for the $\mathrm{UV} / \mathrm{TiO}_{2}$ process, respectively. But, with respect to the values in $\mathrm{UV} /$ $\mathrm{TiO}_{2}$, the dechlorination ratios in $\mathrm{O}_{3}$ and $\mathrm{O}_{3} / \mathrm{UV} / \mathrm{TiO}_{2}$ started to decline from $80 \mathrm{~min}$. and continued to the end. Since the detected aliphatic intermediates were carboxylic acids, presumably only the aromatic intermediates were chlorinated. The smallest dechlorinations in $\mathrm{UV} / \mathrm{TiO}_{2}$ can be attributed to a very slow 2, 4-D decay and formation of 2, 4-DCP, which was the only aromatic intermediate and considered to be more resistant to degradation than 2, 4-D. The enhanced dechlorination in $\mathrm{O}_{3}$, despite the selective reaction of ozone with organic compounds, may be attributed to relatively large ozone supply rate $(\approx 2.0 \mathrm{mg} / \mathrm{L} / \mathrm{min}$.). The two apparently major unidentified aromatics (RT $\approx 4.5 \mathrm{~min}$. and $6.6 \mathrm{~min}$.) in the $\mathrm{O}_{3}$ process (Fig. 4) could be chlorinated in addition to 2, 4-DCP. The relatively slow 2, 4-D decay and the formation of possibly chlorinated aromatics in significant amounts in $\mathrm{O}_{3}$ resulted in smaller dechlorinations compared to the values in $\mathrm{O}_{3} / \mathrm{UV} / \mathrm{TiO}_{2}$. Detection the aromatic intermediates, including 2, 4-DCP, only for a short period and at very low concentrations, exhibited that dechlorination was presumably the first and/or major step in the $\mathrm{O}_{3} / \mathrm{UV} / \mathrm{TiO}_{2}$ process. The largest dechlorination values in $\mathrm{O}_{3} / \mathrm{UV} / \mathrm{TiO}_{2}$ can obviously be attributed to a large number of $\mathrm{OH}$ generation, its high oxidation potential and non-selective reactions with 2, 4-D and its chlorinated aromatic intermediates. Despite complete disappearance of 2, 4-D and its aromatic intermediates, the dechlorination values were less than $90 \%$ in the $\mathrm{O}_{3} / \mathrm{UV} / \mathrm{TiO}_{2}$ process by the end of the experiments. Reaction between chloride ions and OH resulting in the reduced chloride concentrations may be ruled out in this case because the reaction is considered to be significant at high $(\geq 0.1 \mathrm{M})$ chloride concentrations only (Kiwi, et al., 2000). The dechlorination values could have been underestimated, since the background chloride concentrations (before oxidation), which varied between $5 \%$ and $7 \%$, were taken as zero in all of the experiments. The relatively larger background chloride concentrations may be the result of agitation of 2, 4-D solution due to mixing (all experiments) and air flow (experiments involving $\mathrm{O}_{3}$ ) before commencing the experiments.

In aqueous solution, mineralization of low concentration 2, 4-D $(\approx 45 \mu \mathrm{M})$ by the $\mathrm{O}_{3}, \mathrm{UV} / \mathrm{TiO}_{2}$ and $\mathrm{O}_{3} / \mathrm{UV} / \mathrm{TiO}_{2}$ processes was investigated, using the world's first high-strength fiber catalyst. 2, 4-D degradation and TOC removal followed pseudo firstorder reaction kinetic while the mineralization was greatly enhanced in $\mathrm{O}_{3} / \mathrm{UV} / \mathrm{TiO}_{2}$. The removal rates for 2, 4-D and TOC in $\mathrm{O}_{3} / \mathrm{UV} / \mathrm{TiO}_{2}$ were about 1.5 and 2.4-folds larger than the summation of the corresponding values for $\mathrm{O}_{3}$ and $\mathrm{UV} / \mathrm{TiO}_{2}$. The $\mathrm{O}_{3} / \mathrm{UV} /$ $\mathrm{TiO}_{2}$ process was characterized by a few aromatic intermediates and their short lives, fast degradations of the aliphatic intermediates despite their presence in a relatively larger number and dechlorination as a major step in the mineralization. The enhanced dechlorination and 2, 4-D mineralization in the $\mathrm{O}_{3} / \mathrm{UV} / \mathrm{TiO}_{2}$ process were due to the increased ozone decomposition and the reduced electron-hole recombination on $\mathrm{TiO}_{2}$ surface resulting in a large number of $\mathrm{OH}$ generation. The results exhibited that photocatalytic ozonation with $\mathrm{TiO}_{2}$ fiber catalyst is very promising to overcome the problems being faced in AOP using $\mathrm{TiO}_{2}$ as a photocatalyst: separation of catalyst in suspension and reduced efficiency of immobilized catalyst (e.g. $\mathrm{TiO}_{2}$ film/fiber).

\section{ACKNOWLEDGMENT}

The authors would like to thank Ube Industries Ltd., Yamaguchi, Japan, for providing the $\mathrm{TiO}_{2}$ fiber catalyst used in this investigation.

\section{REFERENCES}

Agustina, T. E.; Ang, H. M.; Vareek, V. K., (2005). A review of synergistic effect of photocatalysis and ozonation on wastewater treatment. J. Photoch. Photobio. C., 6, 264273.

Brillas, E.; Calpe, J. C.; Cabot, P., (2003). Degradation of the herbicide 2,4-dichlorophenoxyacetic acid by ozonation catalyzed with $\mathrm{Fe}^{2+}$ and UVA light. Appl. Catal. B., 46, 381391.

Beltran, F. J.; Rivas, F. J.; Gimeno, O., (2005). Comparison between photocatalytic ozonation and other oxidation processes for the removal of phenols from water. J. Chem. Tech. Biotech., 80, 973-984.

Djebbar, K.; Sehili, T., (1998). Kinetics of heterogeneous photocatalytic decomposition of 2,4-dichlorophenoxyacetic acid over titanium dioxide and zinc oxide in aqueous solution. Pestic. Sci., 54, 269-276.

Drzewicz, P.; Trojanowicz, M.; Zona, R.; Solar, S.; Gehringer, P., (2004). Decomposition of 2,4-dichlorophenoxyacetic 


\section{R. R. Giri, et al.}

acid by ozonation, ionizing radiation as well as ozonation combined with ionizing radiation. Radiat. Phys. Chem., 69, 281-287.

Farre, M. J.; Franch, M. I.; Malato, S.; Ayllon, J. A.; Peral, J.; Domenech, X., (2005). Degradation of some biorecalcitrant pesticides by homogeneous and heterogeneous photocatalytic ozonation. Chemosphere, 58, 1127-1133.

Ishikawa, T., (2004). Photocatalytic fiber with gradient surface structure produced from a polycarbosilane and its applications. Int. J. Appl. Ceram. Tech., 1(1), 49-55.

Haag, W. R.; Yao, C. C. D., (1992). Rate constants for reaction of hydroxyl radicals with several drinking water contaminants. Environ. Sci. Tech., 26, 1005-1013.

Jung, O., (2001). Destruction of 2-chlorophenol from wastewater and investigation of byproducts by ozonation. Bull. Korean Chem. Soc., 22(8), 850-856.

Kiwi, J.; Lopez, A.; Nadtochenko, V., (2000). Mechanism and kinetics of the OH-radical intervention during Fenton oxidation in the presence of a significant amount of radical scavenger $\left(\mathrm{Cl}^{-}\right)$. Environ. Sci. Tech., 34, 2162-2168.
Li, L.; Zhu, W., Chen, L.; Zhang, P.; Chen, Z., (2005). Photocatalytic ozonation of dibutyl phthalate over $\mathrm{TiO}_{2}$ film. J. Photoch. Photobiol. A, 175, 172-177.

Munter, R., (2001). Advanced oxidation processes: current status and prospects. Proc. Estonian Acad. Sci., Chem., 50(2), 59-80.

Singh, H. K.; Muneer, M., (2004). Photodegradation of a herbicide derivative, 2, 4-dichlorophenoxyacetic acid in aqueous suspension of titanium dioxide. Res. Chem. Intermediat., 30(3), 317-329.

Terashima, Y.; Ozaki, H.; Giri, R. R.; Tano, T.; Nakatsuji, S.; Takanami, R.; Taniguchi, S., (2006). Photocatalytic oxidation of low concentration of 2, 4-D solution with new $\mathrm{TiO}_{2}$ fiber catalyst in a continuous flow reactor. Water Sci. Tech., 54(8), 55-63.

Yao, J.; Huang, Z.; Masten, S. J., (1998). The ozonation of pyrene: pathway and product identification. Water Res., 32(10), 3001-3012.

\section{AUTHOR (S) BIOSKETCHES}

Giri, R. R., Ph.D., Researcher, New Industrial R and D Center, Osaka Sangyo University, 3-1-1 Nakagaito, Daito City, 574-8530 Osaka, Japan. Email: rabindra@cnt.osaka-sandai.ac.jp

Ozaki, H., D.Eng, Professor, Department of Civil Engineering, Osaka Sangyo University, 3-1-1 Nakagaito, Daito City, 574-8530 Osaka, Japan. Email: ozaki@ce.osaka-sandai.ac.jp

Taniguchi, S., M.Sc., Researcher, New Industrial R and D Center, Osaka Sangyo University, 3-1-1 Nakagaito, Daito City, 574-8530 Osaka, Japan, Email: taniguch@cnt.osaka-sandai.ac.jp

Takanami, R., M.Sc., Researcher, New Industrial R and D Center, Osaka Sangyo University, 3-1-1 Nakagaito, Daito City, 574-8530 Osaka, Japan. Email: r-nami@cnt.osaka-sandai.ac.jp

This article should be referenced as follows:

Giri, R. R.; Ozaki, H.; Taniguchi, S.; Takanami, R., (2008). Photocatalytic ozonation of 2,4-dichlorophenoxyacetic acid in water with a new $\mathrm{TiO}_{2}$ fiber. Int. J. Environ. Sci. Tech., 5(1), 17-26. 